\title{
Simultaneous Waste Water Purification via Photocatalysis and Seed Germination
}

\author{
Sadhana A. Sawant ${ }^{1}$, Ajinkya Nene ${ }^{2}$, Savita P. Somani ${ }^{2}$, \\ Shreeniwas K. Omanwar ${ }^{3}$, Prakash R. Somani ${ }^{2,4^{*}}$ \\ ${ }^{1}$ Smt. Kashibai Navale College of Engineering, Pune, India \\ ${ }^{2}$ Applied Science Innovations Pvt. Ltd., Pune, India \\ ${ }^{3}$ Department of Physics, Sant Gadge Baba Amravati University, Amravati, India \\ ${ }^{4}$ College of Engineering, Bharati Vidyapeeth University, Pune, India \\ Email: "psomani1@yahoo.com
}

Received February 25, 2013; revised March 28, 2013; accepted April 7, 2013

Copyright (C) 2013 Sadhana A. Sawant et al. This is an open access article distributed under the Creative Commons Attribution License, which permits unrestricted use, distribution, and reproduction in any medium, provided the original work is properly cited.

\begin{abstract}
Preliminary results of our study related to simultaneous waste water purification by photocatalytic degradation of organic impurity (Methylene Blue dye) and its effects on seed germination are presented here. It is interesting and important to know that complete degradation of the dye occurs within 2 hours and does not adversely affect the seed germination process. It is concluded that waste water purification by photocatalysis and seed germination (agriculture) can be carried out simultaneously, opening a way for advanced agriculture.
\end{abstract}

Keywords: Water Purification; Photocatalysis; Solar Energy; Agriculture; Seed Germination.

\section{Introduction}

Since the first report of Fujishima and Honda in 1972 [1], lots of work had been carried out on photocatalysis with major emphasis on waste water treatment [2-8]. Materials thoroughly studied for photocatalytic use are $\mathrm{TiO}_{2}$ and $\mathrm{ZnO}$ [9-12]. Several other materials like $\mathrm{Bi}_{2} \mathrm{MoO}_{6}$, $\mathrm{Bi}_{2} \mathrm{WO}_{6}, \mathrm{BiVO}_{4}, \mathrm{CdS}, \mathrm{WO}_{3}, \mathrm{KTiNbO}_{5}$ etc. have been studied for their photocatalytic property [13-17].

Process designed for water reclamation and its subsequent use is as follows. Waste water from industries, households and other sources will be going to a Photocatalytic treatment plant where it will be treated and purified. Other techniques and technologies like activated carbon adsorption, UV-treatment, membrane technology, and ozonation etc. may or may not be used in this treatment plant in addition to Photocatlytic treatment. Such treated water will then go for potable or non-potable use like agriculture - depending on its purity.

The basic process involved in agriculture is seed germination and growth and we were interested to know if the waste water treatment (by photocatalytic means) and seed germination can occur simultaneously. Via this communication, we present our preliminary results on simultaneous waste water purification by photocatalytic

"Corresponding author. action and seed germination process. Methylene Blue (MB) dye is used as a pollutant. Although Methylene Blue dye is not that poisonous so as to kill/inactivate the seed germination process, it has indeed given us lots of insight towards our aim.

\section{Experimental}

Commercially available $\mathrm{TiO}_{2}$ (Hexon Laboratories Pvt. Ltd., India) is used as a photocatalyst which was used as received. Experiments were done in a glass tank (Length $\times$ Width $\times$ Height $=47 \mathrm{~cm} \times 8 \mathrm{~cm} \times 35 \mathrm{~cm}$ ). Sweet corn seeds were used for studying the seed germination process and the effect of simultaneous photocatalytic degradation of organic waste material. Methylene Blue (MB) dye is used as an organic waste which is photocatalytically degraded using $\mathrm{TiO}_{2}$ as a photocatalyst. All experiments were done under direct sunlight. During the experiments, seeds were protected from the direct sunlight by covering them with a paper. However, seeds were in contact with air throughout the experiments. Twenty (20) seeds were used each time for study. Methylene Blue solution $(1 \mathrm{~L})$ concentration $\left(2.5 \times 10^{-2} \mathrm{mM}\right)$ and amount of $\mathrm{TiO}_{2}(3 \mathrm{gm})$ was kept same throughout all experiments. Stirring was continuously done using an electronic stirrer. Molecular structure of the Methylene Blue dye is shown 
in Figure 1. Two sets of experiments were done viz. with and without using the Germination paper.

In the first set of experiment, germination paper (which is usually used by researchers while studying the seed germination process) is put in the sieve and the same is kept in contact with the Methylene Blue dye solution (containing $\mathrm{TiO}_{2}$ photocatalyst) under sunlight as shown in Figure 2(a).

Second set of the experiment is done in exactly the same manner as first; except that germination paper was not used. Here, the seeds were kept on the sieve and were in direct contact with the Methylene Blue dye solution containing $\mathrm{TiO}_{2}$ photocatalyst.

In both the set of experiments, continuous monitoring/observations were made regarding the time within which the Methylene Blue dye solution becomes completely colorless; the process of seed germination is studied by noting the number of seeds which got germinated, measuring the root and shoot lengths on each day - until $7^{\text {th }}$ day from the start of the experiment. Seeds were numbered for this purpose from 1 to 20 . Observations were also made if the seed coat of the seeds has got blue color-due to absorption of Methylene Blue dye from the solution. Comparison of the observations of the two set of experiments were used to draw conclusions.

\section{Results and Discussion}

Figure 2(a) shows the simultaneous photocatalysis and seed germination experiment using Germination paper. Blue color of the solution is due to Methylene Blue dye. After 90 min under natural sunlight, MB dye is observed to degrade completely and the blue color of the solution disappears. White color of the solution as in Figure 2(b) is due to the dispersed $\mathrm{TiO}_{2}$. Figure 2(c) shows the photograph of the seeds germinated after seven days. It is observed that total eleven (11) seeds get germinated during this set of experiment.

All germinated seeds show development of root and shoot parts. Multiple roots are observed on each seed with varying lengths while only one shoot was developed. The longest root is used for measurement. The length of the root and shoot are measured with the help of a thread - since the roots are observed to be curvy. Observable growth of the root and shoot was observed only after 3 days. No blue color was observed on the seed coat of the seeds (either front or even back side), indicating thereby that Methylene Blue dye is not absorbed directly by the

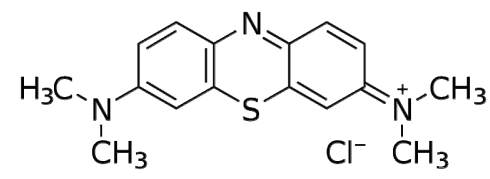

Figure 1. Molecular structure of Methylene Blue (MB) dye.

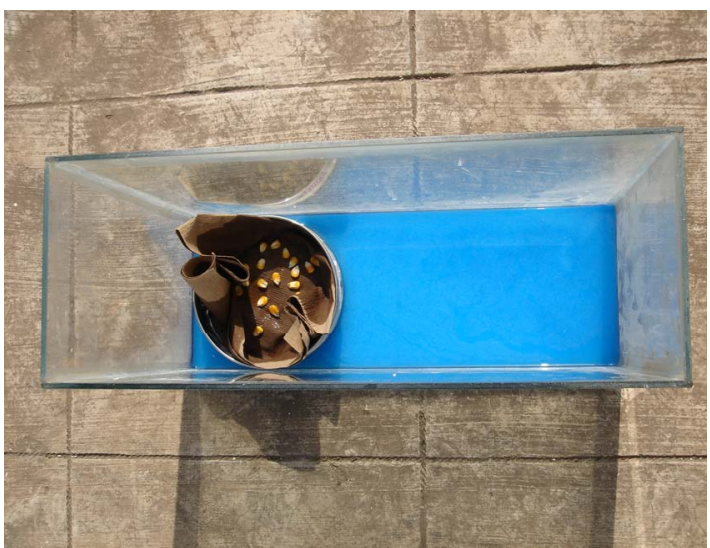

(a)

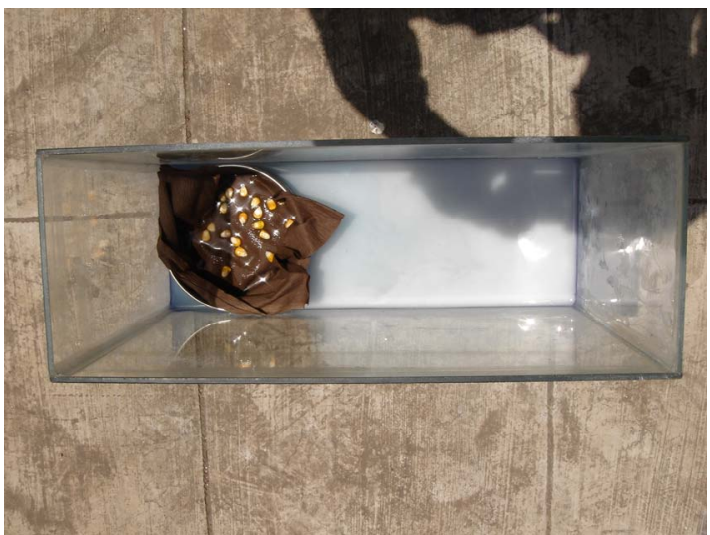

(b)

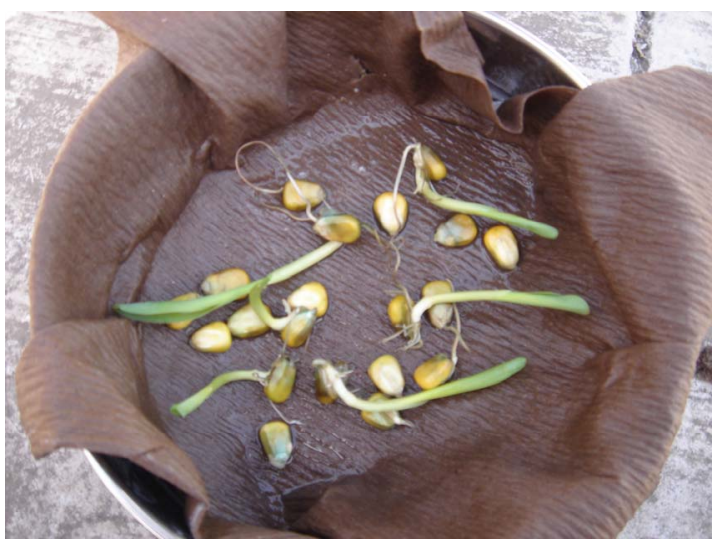

(c)

Figure 2. Simultaneous photocatalysis and seed germination experiment using germination paper: (a) At the start of the experiment-showing blue color of the solution; (b) After 90 min-showing complete degradation of MB dye. White color is due to presence of $\mathrm{TiO}_{2}$; (c) Seeds germinatedafter 7 days.

seeds or seed coats. This is due to the fact that the germination paper does not allow the Methylene Blue dye to reach to the seeds. The second possibility is that the dye gets degraded completely before absorption by the seeds.

In order to understand further, another set of experi- 
ment was done with the same experimental parameters, without using the germination paper. Here, the seeds were kept on the sieve and kept in contact with the Methylene Blue dye solution containing $\mathrm{TiO}_{2}$ photocatalyst. Seeds were kept in such a way that lower surface of the seeds were making a direct contact with the dye solution whereas upper surface with air. After 90 min under natural sunlight, Methylene Blue dye is observed to degrade completely and the blue color of the solution disappears - as shown in Figure 3(a). White color is due to dispersed $\mathrm{TiO}_{2}$.

In all, nine (9) seeds were observed to get germinated. Lower surface of the seeds/seed coats were observed to be blue in color which is due to absorption of the Methylene Blue dye. However, the blue color was only localized to the lower surface and do not gets penetrated throughout the seed.

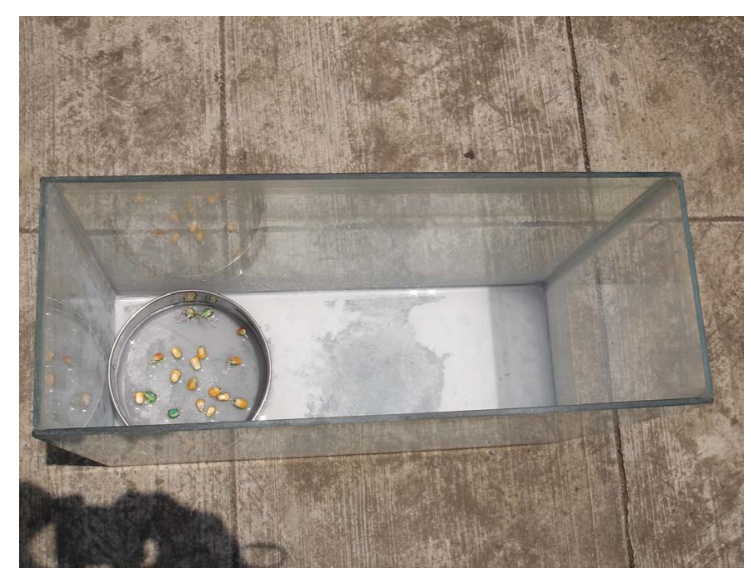

(a)

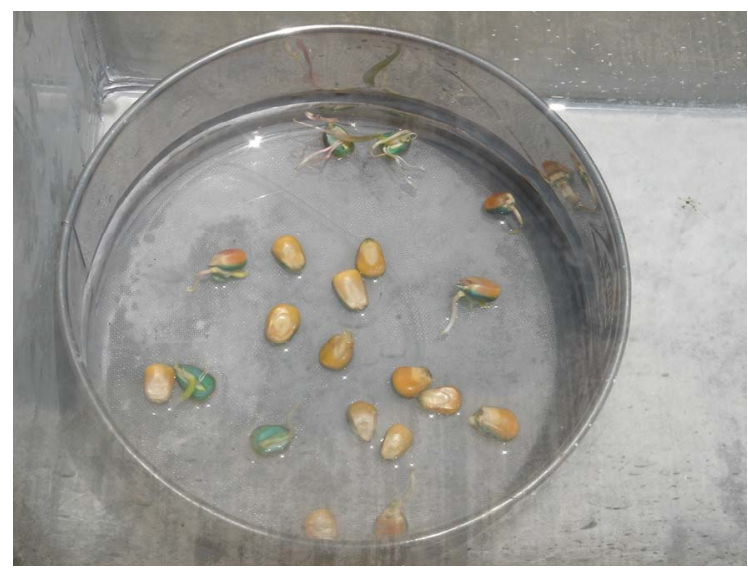

(b)

Figure 3. Simultaneous photocatalysis and seed germination experiment without germination paper: (a) After $90 \mathrm{~min}$-showing complete degradation of MB dye. White color is due to presence of $\mathrm{TiO}_{2}$; (b) Seeds germinated-after 7 days. It is observable that only the back surface of the seed coat of few seeds has got blue color due to absorption of MB dye.
Seed germination process was measured in terms of number of seeds germinated, average length roots and average length of shoots. Out of the multiple roots on a seed, the longest root is considered. Comparison of the results obtained in the two set of experiments (i.e. with and without using the germination paper) are shown in Table 1. Following observations are made. The germination process in both the experiments has started on the forth day from the start of the experiment. No observable/measurable development of the root(s) or shoot has been observed in both the experiments for the first three days. Germination process is observed to be started on all 11 seeds germinated in the Experiment-1 (with germination paper) from the $4^{\text {th }}$ day of the experiment. In Experiment-2 (without germination paper), 3 seeds starts germinating on the $4^{\text {th }}$ day and then this number increasing to nine on the $5^{\text {th }}$ day, which remains the same even on the $7^{\text {th }}$ day.

The total number of seeds that have got germinated in Experiment-1 (i.e. germinated seeds $=11$ ) and Experiment-2 (i.e. germinated seeds $=9$ ) are approximately/experimentally same (at least comparable). Comparison of the root and shoot length in both the experiments on each day indicates that the seed germination process in Experiment-2 is slow. Although, it is very difficult (at present) to point out the exact reason for the slow seed germination in Experiment-2, we speculate the possibility of the following reasons: 1) Seeds in Experiment-2 were directly in contact with plenty of water which may have resulted in over absorption of water by seeds; 2) Seeds were directly in contact with $\mathrm{TiO}_{2}-$ a photocatalytic material which can kill the organics. However, it is important to point out here that we observed no signs of damage to the seeds by say $\mathrm{TiO}_{2}$.

Although Methylene Blue dye is not that poisonous so as to kill/inactivate the seed germination process completely; it has indeed given us lots of insight towards our aim. We are planning our future experiments with a poisonous organic compound that can inactivate the seed germination process. Via this, we want to understand the time within which the complete degradation of this poisonous organic material (pollutant) should happen by photocatalysis action in order that the seed germination process can progress.

It is safe to conclude here that simultaneous waste water purification by photocatalytic degradation of organic/hazardous waste materials and seed germination is possible. Further, our observations indicate that the photocatalytic degradation process should get completed within about $90 \mathrm{~min}$. maximum time. Our present experiment and observations may lead to advanced agricultural processes in which waste water purification and agriculture (via seed germination) can simultaneously be done. 
Table 1. Comparison of the seed germination process in the two set of experiments.

\begin{tabular}{|c|c|c|c|c|c|c|}
\hline \multirow[b]{2}{*}{ Day } & \multicolumn{3}{|c|}{ Experiment-1 (With Germination Paper) } & \multicolumn{3}{|c|}{ Experiment-2 (No Germination Paper) } \\
\hline & $\begin{array}{c}\text { Number of Seeds } \\
\text { Germinated }\end{array}$ & $\begin{array}{l}\text { Average Root } \\
\text { Length }\end{array}$ & $\begin{array}{l}\text { Average Shoot } \\
\text { Length }\end{array}$ & $\begin{array}{c}\text { Number of Seeds } \\
\text { Germinated }\end{array}$ & $\begin{array}{l}\text { Average Root } \\
\text { Length }\end{array}$ & $\begin{array}{l}\text { Average Shoot } \\
\text { Length }\end{array}$ \\
\hline $1^{\text {st }}$ day & 0 & 0 & 0 & 0 & 0 & 0 \\
\hline $2^{\text {nd }}$ day & 0 & 0 & 0 & 0 & 0 & 0 \\
\hline $3^{\text {rd }}$ day & 0 & 0 & 0 & 0 & 0 & 0 \\
\hline $4^{\text {th }}$ day & 11 & $2.64 \mathrm{~cm}$ & $1.6 \mathrm{~cm}$ & 3 & $1.8 \mathrm{~cm}$ & $0.63 \mathrm{~cm}$ \\
\hline $5^{\text {th }}$ day & 11 & $2.78 \mathrm{~cm}$ & $3.55 \mathrm{~cm}$ & 9 & $1.4 \mathrm{~cm}$ & $0.96 \mathrm{~cm}$ \\
\hline $7^{\text {th }}$ day & 11 & 3.1 & $5.7 \mathrm{~cm}$ & 9 & $2.6 \mathrm{~cm}$ & $3.3 \mathrm{~cm}$ \\
\hline
\end{tabular}

\section{Conclusion}

We conclude here that simultaneous waste water purification by photocatalytic degradation of organic/hazardous waste materials and seed germination is possible. Further, our observations indicate that the photocatalytic degradation process should get completed within about 90 min. maximum time - so that it does not affect the seed germination process adversely.

\section{REFERENCES}

[1] A. Fujishima and K. Honda, "Electrochemical Photolysis of Water at a Semiconductor Electrode," Nature, Vol. 238, No. 5358, 1972, pp. 37-38. doi:10.1038/238037a0

[2] M. R. Hoffmann, S. T. Martin, W. Choi and D. W. Bahnemann, "Environmental Applications of Semiconductor Photocatalysis," Chemical Reviews, Vol. 95, No. 1, 1995, pp. 69-96. doi:10.1021/cr00033a004

[3] K. Hashimoto, H. Irie and A. Fujishima, "TiO 2 Photocatalysis: A Historical Overview and Future Prospects," Japanese Journal of Applied Physics, Vol. 44, No. 12, 2005, pp. 8269-8285. doi:10.1143/JJAP.44.8269

[4] M. N. Chong, B. Jin, C. W. K. Chow and C. Saint, "Recent Developments in Photocatalytic Water Treatment Technology: A Review," Water Research, Vol. 44, No. 10, 2010, pp. 2997-3027. doi:10.1016/j.watres.2010.02.039

[5] U. G. Akpan and B. H. Hameed, "Parameters Affecting the Photocatalytic Degradation of Dyes Using $\mathrm{TiO}_{2-}$ Based Photocatalysts: A Review," Journal of Hazardous Materials Vol. 170, No. 2-3, 2009, pp. 520-529. doi:10.1016/j.jhazmat.2009.05.039

[6] M. M. Ba-Abbada, A. A. H. Kadhum, A. B. Mohamad, M. S. Takriff and K. Sopian, "Solar Photocatalytic Degradation of Environmental Pollutants Using ZnO Prepared by Sol-Gel: 2,4-Dichlorophenol as Case Study," International Journal of Thermal \& Environmental Engineering, Vol. 1, No. 1, 2010, pp. 37-42. doi:10.5383/ijtee.01.01.006

[7] Y. Izumi, "Recent Advances in the Photocatalytic Conversion of Carbon Dioxide to Fuels with Water and/or Hydrogen Using Solar Energy and Beyond," Coordination Chemistry Reviews, Vol. 257, No. 1, 2013, pp. 171-
186. doi:10.1016/j.ccr.2012.04.018

[8] K. Kabra, R. Chaudhary and R. L. Sawhney, "Treatment of Hazardous Organic and Inorganic Compounds through Aqueous-Phase Photocatalysis: A Review," Industrial \& Engineering Chemistry Research, Vol. 43, No. 24, 2004, pp. 7683-7696. doi:10.1021/ie0498551

[9] S. Buzby, M. A. Barakat, H. Lin, C. Ni, S. A. Rykov, J. G. Chen and S. I. Shah, "Visible Light Photocatalysis with Nitrogen-Doped Titanium Dioxide Nanoparticles Prepared by Plasma Assisted Chemical Vapor Deposition," Journal of Vacuum Science \& Technology B, Vol. 24, No. 3, 2006, pp. 1210-1214. doi:10.1116/1.2192544

[10] J. Lee, H. S. Shim, M. Lee, J. K. Song and D. Lee, "SizeControlled Electron Transfer and Photocatalytic Activity of $\mathrm{ZnO}-\mathrm{Au}$ Nanoparticle Composites," The Journal of Physical Chemistry Letters, Vol. 2, No. 22, 2011, pp. 2840-2845. doi:10.1021/jz2013352

[11] H. Chang, C. Su, C. H. Lo, L. C. Chen, T. T. Tsung and C. S. Jwo, "Photodecomposition and Surface Adsorption of Methylene Blue on $\mathrm{TiO}_{2}$ Nanofluid Prepared by ASNSS," Materials Transactions, Vol. 45, No. 12, 2004, pp. 33343337. doi:10.2320/matertrans. 45.3334

[12] B. Neppolian, H. Jung and H. Choi, "Photocatalytic Degradation of 4 Chlorophenol Using $\mathrm{TiO}_{2}$ and $\mathrm{Pt}_{\mathrm{TiO}}$ Prepared by Sol Gel Method," Journal of Advanced Oxidation Technologies, Vol. 10, No. 2, 2007, pp. 001-006.

[13] G. Y. Yan, L. P. Zheng, L. S. Xie, X. L. Weng and J. H. $\mathrm{Ye}$, "Nature of Ag-Bi-Codoped $\mathrm{TiO}_{2}$ Visible Light Photocatalyst," Rare Metals, Vol. 30, Supplement 1, 2011, pp. 259-266. doi:10.1007/s12598-011-0281-x

[14] H. H. Li, C. Y. Liu, K. W. Li and H. Wang, "Preparation, Characterization and Photocatalytic Properties of Nanoplate $\mathrm{Bi}_{2} \mathrm{MoO}_{6}$ Catalysts," Journal of Materials Science, Vol. 43, No. 22, 2008, pp. 7026-7034. doi:10.1007/s10853-008-3034-y

[15] J. Zhu, J.-G. Wang, Z.-F. Bian, F.-G. Cao and H.-X. Li, "Solvothermal Synthesis of Highly Active $\mathrm{Bi}_{2} \mathrm{WO}_{6}$ Visible Photocatalyst," Research on Chemical Intermediates, Vol. 35, No. 6-7, 2009, pp. 799-806. doi:10.1007/s11164-009-0099-4

[16] Y. Zhang, J. Q. Yu, D. S. Yu, X. C. Zhou and W. Lu, "Enhancement in the Photocatalytic and Photoelectrochemical Properties of Visible Light Driven $\mathrm{BiVO}_{4}$ Photocatalyst," Rare Metals, Vol. 30, Supplement 1, 2011, pp. 
192-198.

[17] K. Inoue, S. Suzuki and M. Nagai, "Ion Exchanged Potassium Titanoniobate as Photocatalyst under Visible
Light" Journal of Electroceramics, Vol. 24, No. 2, 2010 , pp. 110-114. doi:10.1007/s10832-008-9558-3 